Brauer PR 1984 Use of collagen gel cultures to study heart development: proteoglycan and glycoprotein interactions during the formation of endocardial cushion tissue. In: Trelstad RL (ed) The Role of Extracellular Matrix in Development. Alan R Liss, New York, pp 323-350

10. Inoue H, Zipes DP 1987 Conduction over an isthmus of atrial myocardium in vivo: a possible model of Wolff-Parkinson-White syndrome. Circulation 76:637-647

11. Klein GJ, Guiraudon GM, Kerr CR, Sharma AD, Yee R, Szabo T, Yeung Lai Wah JA 1988 "Nodoventricular" accessory pathway: evidence for a distinct accessory atrioventricular pathway with atrioventricular node-like properties. J Am Coll Cardiol 11:1035-1040

12. Robkin MA, Shepard TM, Tanimura T 1972 A new in vitro culture technique for rat embryos. Teratology 5:367-376
13. Canale E, Smolich JJ, Campbell GR 1987 Differentiation and innervation of the atrioventricular bundle and ventricular Purkinje system in sheep heart. Development 100:641-651

14. de Groot IJM, Sanders E, Visser SD, Lamers WH, de Jong F, Los JA, Moorman AFM 1987 Isomyosin expression in developing chicken atria: a marker for the development of conductive tissue? Anat Embryol (Berl) 176:515-523

15. Vassall-Adams PR 1982 The development of the atrioventricular bundle and its branches in the avian heart. J Anat 134:169-183

16. Van Mierop LHS, Bertuch CJ 1971 Development of arterial blood pressure in the chick embryo. Am J Physiol 212:43-48

17. Ruckman RN, Cassling RJ, Clark EB, Rosenquist GC 1981 Cardiac function in the embryonic chick. In: Pexieder $\mathrm{T}$ (ed) Perspectives in Cardiovascular Research. Raven Press, New York, pp 401-417

\title{
Announcement
}

\section{Joint PhD-Fellowship Training Program}

The University of Chicago Department of Pediatrics announces its unique, new Pediatric Science Training/ $\mathrm{PhD}$ Program. Trainees wishing to pursue an academic career may simultaneously pursue subspecialty training and a graduate school program leading to the $\mathrm{PhD}$ degree in this 5-year program. Training is available in most pediatric subspecialties, and research opportunities are available in diverse fields, including the social and behavioral sciences as well as the biologic sciences. Applications are being accepted for 1991. This program is funded by the National Institutes of Child Health and Human Development. Consequently, the program is only open to U.S. citizens or permanent residents. Address inquiries to: Robert L. Rosenfield, M.D., Program Director, Pediatric Science Training/PhD Program, Wyler Children's Hospital, 5841 South Maryland, Chicago, IL 60637. 